\title{
Análise da inserção ocupacional dos jovens no Paraná
}

\author{
Vinícius Misael Alves de Lima* \\ Nadja Simone Menezes Nery de Oliveira** \\ Solange de Cassia Inforzato de Souza ${ }^{* * * *}$ \\ Katy Maia ${ }^{* * * *}$
}

Resumo: O presente estudo busca investigar os determinantes da inserção ocupacional dos jovens no Paraná, de 15 a 24 anos, com base nos microdados da Pesquisa Nacional por Amostra de Domicílio (PNAD), no ano de 2011. Os principais resultados obtidos a partir do uso do modelo logit multinomial mostraram que as chances das jovens do sexo feminino apenas estudarem são maiores, e as dos homens são trabalhar ou trabalhar e estudar; à medida que o jovem envelhece as chances de trabalhar e deixar de estudar aumentam. Jovens que possuem uma menor escolaridade e que vivem com companheiro(a) ou cônjuge tem uma maior probabilidade de abandonarem os estudos; a probabilidade de realizar ambas as atividades, e de não realizar nenhuma atividade, aumenta quando o jovem reside na área metropolitana do Estado.

Palavras-chave: Modelo logit Multinomial, ocupação, Paraná.

Classificação JEL: J22.

\footnotetext{
* Economista pela Universidade Federal do Mato Grosso do Sul (UFMS) e Mestre em Economia Regional pela Universidade Estadual de Londrina (UEL). E-mail: viniciusmisael@gmail.com

**Economista pela Universidade Federal da Paraíba (UFPB), Mestre em Economia Regional pela

Universidade Estadual de Londrina (UEL) e Doutoranda do Programa de Pós-graduação em Desenvolvimento Regional e Agronegócio (PPGDRA) da Universidade do Oeste do Paraná (UNIOESTE).

E-mail: nadja_menezes@hotmail.com

***Doutora em Educação pela Pontifícia Universidade Católica de São Paulo. Professora associada do

Departamento de Economia da Universidade Estadual de Londrina E-mail: solangecassia@uol.com.br ****Doutora em Economia pela Universidade de Brasília .Professora adjunta do Departamento de

Economia da Universidade Estadual de londrina E-mail: katymaia@terra.com.br
} 


\title{
Analysis of occupational insertion of young people in Paraná
}

\begin{abstract}
This study investigates the determinants of occupational integration of young people in Paraná, 15 to 24 years old, based on microdata from the PNAD, in the year 2011. The main results obtained from the use of the model multinomial logit showed that the chances of young women are just larger study, and men are working or working and studying; as the young ages the chance to work and stop studying increase. Young people who have less education and living with a partner (a) or spouse has a higher probability of leaving the studies, the probability of performing both activities, and do not perform any activity increases when young lives in the metropolitan area of the State.
\end{abstract}

Key-words: Multinomial logit Model; Occupation; Paraná.

JEL Classification: J22.

\section{Introdução}

A juventude manifesta-se como um processo de transição em que os indivíduos saem de uma condição de dependência completa na infância para uma plena autonomia que caracteriza a vida adulta. Esse processo se desenvolve mediante um conjunto de mobilizações que levam o jovem a desenvolver plenamente sua personalidade, a incorporar-se na vida ativa, a ter independência econômica, a constituir um lugar próprio e a estabelecer uma colocação estável (Souza et. al. 2001).

Apesar da redução da participação dos jovens na população brasileira mostrada pelo Censo 2010 em relação ao realizado em 2000, aproximadamente $48,6 \%$ da população é formada por jovens e adolescentes abaixo dos 25 anos, ou seja, quase metade da população. No Paraná, essa parcela corresponde a aproximadamente $40,53 \%$.

É também bastante difundida a relevância da educação dos jovens em vários aspectos da vida econômica e social, conforme documenta os trabalhos de Ferreira e Barros (1999), Lam e Duryea (1999), Mendonça (2000), Santos (2000) e Corseuil et. al. (2001). No entanto, o trabalho em muitos casos é incompatível com a frequência escolar e, assim, os jovens enfrentam o problema de escolher entre o trabalho e o estudo, conciliar ambos ou até, em casos extremos, não estudar nem trabalhar. Algumas pesquisas relevantes podem ser citadas como os de Barros e Mendonça (1991), Leme e Wajnman (2000), Silva e Kassouf (2002), Leite e Silva (2002).

Neste sentido, o presente estudo busca investigar os determinantes da inserção ocupacional dos jovens paranaenses, de 15 e 24 anos, com base nos dados fornecidos pela Pesquisa Nacional por Amostra de Domicílio (PNAD) de 
2011, realizada pelo Instituto Brasileiro de Geografia e Estatística (IBGE).

Além desta introdução, o presente artigo se divide em mais três seções. A seção 2 apresenta a metodologia utilizada e as discussões e os resultados obtidos são tratados na seção 4. Finalmente, a seção 5 sintetiza as conclusões.

\section{Metodologia}

Para alcançar o objetivo proposto foram utilizados os dados da Pesquisa Nacional por Amostra de Domicílio (PNAD), realizada pelo Instituto Brasileiro de Geografia e Estatística (IBGE) no ano de 2011, para o estado do Paraná. Foram analisadas 3.042 observações de jovens com idade entre 15 e 24 anos.

Para a criação da variável dependente, que indica a situação em que o indivíduo se encontra em relação ao estudo e ao trabalho, foram classificados como estudantes aqueles indivíduos que frequentavam a escola ${ }^{1}$ e trabalhadores aqueles que afirmaram que trabalharam durante a semana de referência da pesquisa, de 18 a 24 de setembro de 2011. A variável dependente foi dividida em quatro categorias: não estuda e não trabalha, estuda e não trabalha, não estuda e trabalha e estuda e trabalha. A Tabela 1 apresenta a distribuição dos jovens conforme as categorias: a maioria dos jovens entrevistados somente trabalhava (38\%), enquanto a minoria não estuda e não trabalha (15\%).A tabela 2 exibe as variáveis explicativas avaliadas como determinantes da escolha do indivíduo ${ }^{2}$

Tabela 1: Distribuição de frequência relativa dos jovens por categoria

\begin{tabular}{lc}
\hline \multicolumn{1}{c}{ Categoria } & Frequência relativa \\
\hline Não estuda e não trabalha & $15 \%$ \\
Estuda e não trabalha & $27 \%$ \\
Não estuda e trabalha & $38 \%$ \\
Estuda e trabalha & $20 \%$ \\
\hline Total & $100 \%$ \\
\hline
\end{tabular}

Fonte: Elaborado pelos autores, a partir dos dados da PNAD de 2011.

1 Como escola considera-se desde maternal, jardim de infância etc. até mestrado ou doutorado.

2 Para a escolha das variáveis independentes foram considerados como base os trabalhos de Leite e Silva (2002), Lima e Paixão (2011), Leme e Wajnman (2000), Silva e Kassouf (2002). 
Tabela 2: Descrição das variáveis.

\begin{tabular}{ll}
\hline Variáveis & Descrição \\
\hline Variável Dependente: & $=0$ se não estuda e não trabalha \\
& $=1$ se estuda e não trabalha \\
& $=2$ se não estuda e trabalha \\
& $=3$ se estuda e trabalha \\
\hline Variáveis Independentes: & $=1$ homem \\
sexo* & $=0$ mulher \\
idade & Idade do indivíduo \\
situação* & $=1$ se vive com o cônjuge ou companheiro(a) \\
instr & $=0$ caso contrário** \\
pessoas_dom & Número de anos de estudo \\
metrop* & Número de residentes no domicílio \\
taxa_comodo & $=1$ se o domicílio é na região metropolitana \\
& $=0$ caso contrário \\
\hline
\end{tabular}

Fonte: Elaborado pelos autores, a partir dos dados da PNAD 2011.

Nota: *Variáveis binárias.

**Jovens que já viveram com companheiro(a) mas não vivem mais foram contabilizados nessa categoria.

Utiliza-se, neste estudo, o modelo logit multinomial que calcula a probabilidade condicional de que o indivíduo se encontre em determinada situação, dado que ele possui determinadas características representadas pelo vetor de regressores. $\mathrm{O}$ modelo pode ser expresso da seguinte forma:

$$
\operatorname{Pr}\left(Y_{i}=j \mid X_{i}\right)=\frac{e^{\beta^{\prime}{ }^{\prime} X_{i}}}{\sum_{k=0}^{J} e^{\beta^{\prime} k X_{i}}} \quad \text { para } j=1, \ldots, J, i=1, \ldots, n .
$$

Em que $Y_{i}$ é a variável dependente que indica a situação em que o indivíduo se encontra, $\beta$ representa o vetor de parâmetros a serem estimados que refletem o impacto das alterações em $X_{i}$ na probabilidade de o indivíduo se encontrar numa determinada situação.

A estimação dos parâmetros é feita através da Máxima PseudoVerossimilhança (MPV), proposto por Binder (1983), que leva em consideração o peso amostral de cada indivíduo $\left(w_{i}\right)$. É necessário considerar, ainda, que as variâncias dos estimadores de MPV foram estimadas pelo método de linearização de Taylor ${ }^{3}$, onde o estimador não linear é aproximado por um linear.

A interpretação dos parâmetros do modelo é realizada através da análise

3 Para estimar a variância assintótica dos parâmetros utiliza-se a matriz de primeira ordem da expansão da série de Taylor para o estimador de Máxima Pesudo-Verossimilhança. 
das vantagens e razões de vantagens, bem como da especificação dos efeitos marginais das probabilidades para cada característica do vetor .

\section{Resultados e Discussão}

Nesta seção são descritos e analisados os resultados obtidos no ajustamento do modelo Logit Multinomial. A categoria escolhida como base para estimação do modelo foi a alternativa não estuda e não trabalha. De acordo com o modelo ajustado, a probabilidade de jovens entre 15 e 24 anos, residentes no Paraná, estarem somente estudando é de 18,1\%, enquanto a probabilidade de estarem somente trabalhando é de 43,1\%. A probabilidade de estudar e trabalhar foi estimada em $22,1 \%$ e a de não estarem estudando, nem trabalhando foi de 16,8\%(Tabela 3).

Tabela 3: Probabilidade estimada para cada categoria.

\begin{tabular}{lc}
\hline \multicolumn{1}{c}{ Categoria } & Probabilidade \\
\hline Não estuda e não trabalha & $16,8 \%$ \\
Estuda e não trabalha & $18,1 \%$ \\
Não estuda e trabalha & $43,1 \%$ \\
Estuda e trabalha & $22,0 \%$ \\
\hline Total & $100 \%$ \\
\hline
\end{tabular}

Fonte: Elaborado pelos autores, a partir dos dados da PNAD de 2011.

Os resultados apresentados para o Paraná mostram que as mulheres jovens tem maior chance de estar fora da força de trabalho e dos estudos do que os homens, e também têm uma probabilidade maior de apenas estudar. Já os jovens homens apresentam maiores chances de estarem inseridos no mercado de trabalho, somente trabalhando ou trabalhando e estudando. Ser homem aumenta a probabilidade de estar somente trabalhando em $21,8 \%$ e de estar trabalhando e estudando em 3\%(Tabela 4).

Este fato pode ser explicado, segundo Barros e Mendonça (1991), por um mercado de trabalho menos atraente quando visto pelas jovens mulheres devido aos salários baixos oferecidos a elas. Além disso, os fatores culturais podem estar por trás da menor participação das jovens mulheres no mercado de trabalho, tanto por um tradicional maior envolvimento delas nos afazeres domésticos quanto por um maior não consentimento familiar a certas ocupações e ou locais de trabalho.

É possível verificar que à medida que o jovem envelhece as chances de trabalhar e deixar de estudar aumentam no Paraná. Com 24 anos as chances dos jovens estarem somente trabalhando chegam a 76,2\%, enquanto as chances de estar somente estudando são de 1\% (figura 1). Há uma diminuição de 4,6\% na probabilidade do jovem trabalhar e estudar quando sua idade aumenta em 1 ano (tabela 4). A opção de não estudar e não trabalhar aumenta com o avanço da idade. 
Figura 1: Probabilidades estimadas segundo a idade dos jovens no Paraná.

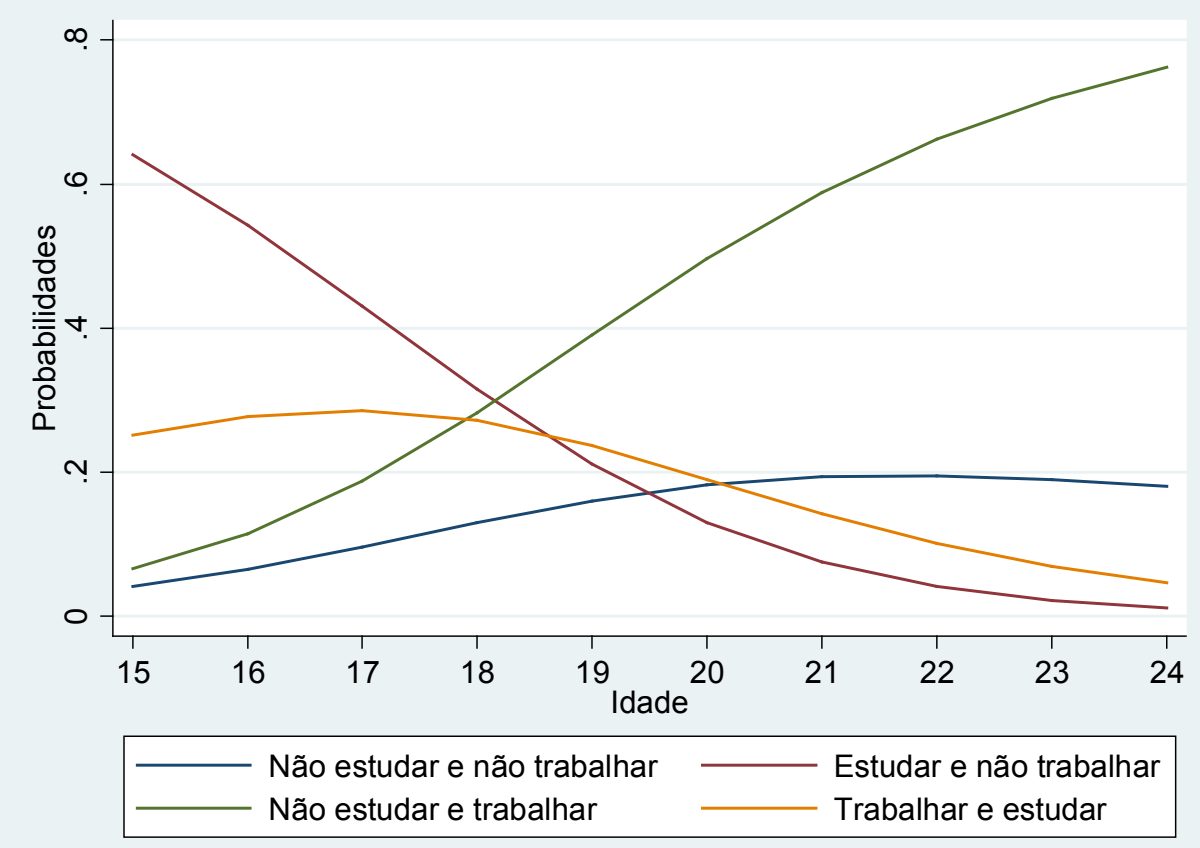

Fonte: Elaborado pelos autores, a partir dos dados da PNAD de 2011.

A explicação para esse resultado pode ser agrupada em três categorias, como expuseram Barros e Mendonça (1991). Em primeiro lugar, com o avanço da idade o mercado de trabalho fica mais atrativo para o jovem: os salários crescem, a oferta de empregos com melhores condições de trabalho tornase mais frequente à medida que as restrições legais ao trabalho tendem a se reduzir quando se consideram menores com idades cada vez mais avançadas. Em segundo lugar, a obrigatoriedade de ir à escola, bem como a sua atratividade, tendem a se reduzir com a idade. A queda da atratividade da escola se deve tanto a repetência quanto a insatisfação ou a desilusão com o sistema educacional. E por último, com a idade o jovem se torna mais independente, buscando um maior orçamento próprio e passando a ter acesso a mais postos de trabalho. Juntando esses três fatores o jovem passa a preferir o trabalho, e o estudo passa a ser uma atividade secundária e noturna.

Outros estudos como os de Barros e Mendonça (1991), Silva e Kassouf (2002) e Leme e Wajnman (2000), mostram evidências para o Brasil e regiões. Barros e Mendonça(1991) com base na PNAD de 1987 para três regiões metropolitanas brasileiras, Fortaleza, Porto Alegre e São Paulo, analisa a alocação de tempo entre estudo e trabalho para crianças de 7 a 12 anos de idade e evidencia que a taxa de participação na força de trabalho e a não frequência escolar são crescentes com a idade e maiores para o gênero masculino, e ainda maiores em São Paulo e Porto Alegre em relação à Fortaleza. Leme e Wajnman (2000) com base nos dados das PNADS de 1981 a 1998 para o Brasil, concluem que ser do sexo masculino reduz a probabilidade de apenas estudar.

O estudo de Silva e Kassouf (2002) analisa os determinantes de alocação 
entre estudo e trabalho de jovens com idade entre 15 e 24 anos e mostram que a parcela de jovens que compõem a população economicamente ativa e que integram a renda familiar é bastante significativa. O jovem entra muito cedo no mercado de trabalho, com $75 \%$ dos jovens no meio rural integrando pela primeira vez a força de trabalho com 12 anos ou menos de idade e no meio urbano cerca de $25 \%$ iniciou com 13 anos ou menos as atividades laborais. Quanto maior a idade do indivíduo jovem, menor é a probabilidade de estudar, independente de fazer parte do mercado de trabalho ou não.

Resultado também importante para o Paraná foi o de que jovens que vivem com companheiro(a) ou cônjuge tem uma maior probabilidade de abandonarem os estudos em relação aos que não estão nessa situação. Conforme a tabela 4 , viver com companheiro(a) diminui a probabilidade de somente estudar em 18,7\%, e de trabalhar e estudar em $8,2 \%$. Para os homens a consequência de viver com companheira ou cônjuge é mais prejudicial, do ponto de vista educacional, em relação às mulheres. Homens, nessa situação, têm uma probabilidade de $64,8 \%$ de estarem somente trabalhando, enquanto as mulheres têm $38,3 \%$ de chance.

Há uma tendência dos jovens deixarem a situação de não estudar nem trabalhar e somente trabalhar à medida que aumenta os seus anos de escolaridade. Na figura 2, constata-se que a escolaridade relativamente baixa dos jovens se constitui, claramente, em uma desvantagem para o indivíduo somente estudar e estudar e trabalhar. Através dos efeitos marginais (tabela 4), constata-se que o aumento em um ano de escolaridade do jovem aumenta a probabilidade de somente estudar e, trabalhar e estudar em 2,1\% e 5,4\%, respectivamente; enquanto reduz as chances de não trabalhar e não estudar e, somente trabalhar em $3,7 \%$ e $3,8 \%$, respectivamente.

Isto pode estar mostrando, conforme esclarece Silva e Kassouf (2002), que o trabalho para estes jovens não prejudica sua escolarização, muito pelo contrário, o trabalho lhes permite o acesso ao sistema escolar, principalmente ao ensino superior, tendo em vista que o estudo requer recursos financeiros, e o trabalho proporciona tal aporte. 
Tabela 4: Estimativas dos efeitos marginais.

\begin{tabular}{|c|c|c|c|c|c|c|c|c|}
\hline & \multicolumn{2}{|c|}{$\begin{array}{l}\text { Não estuda } \\
\text { e não trabalha }\end{array}$} & \multicolumn{2}{|c|}{$\begin{array}{c}\text { Estuda } \\
\text { e não trabalha }\end{array}$} & \multicolumn{2}{|c|}{$\begin{array}{l}\text { Não estuda } \\
\text { e trabalha }\end{array}$} & \multicolumn{2}{|c|}{$\begin{array}{c}\text { Trabalha e } \\
\text { estuda }\end{array}$} \\
\hline & EM & p-valor & EM & p-valor & EM & p-valor & EM & p-valor \\
\hline sexo & $-0,170$ & 0,000 & $-0,074$ & 0,000 & 0,214 & 0,000 & 0,030 & 0,079 \\
\hline idade & 0,024 & 0,000 & $-0,085$ & 0,000 & 0,108 & 0,000 & $-0,046$ & 0,000 \\
\hline situação & 0,119 & 0,000 & $-0,206$ & 0,000 & 0,174 & 0,000 & $-0,087$ & 0,000 \\
\hline instr & $-0,037$ & 0,000 & 0,021 & 0,000 & $-0,038$ & 0,000 & 0,054 & 0,000 \\
\hline $\begin{array}{l}\text { pessoas_ } \\
\text { dom }\end{array}$ & 0,021 & 0,000 & 0,004 & 0,369 & $-0,008$ & 0,274 & $-0,017$ & 0,006 \\
\hline metrop & 0,026 & 0,150 & $-0,020$ & 0,301 & $-0,034$ & 0,185 & 0,027 & 0,160 \\
\hline $\begin{array}{l}\text { taxa_ } \\
\text { comodo }\end{array}$ & $-0,044$ & 0,542 & $-0,379$ & 0,000 & 0,415 & 0,000 & 0,009 & 0,917 \\
\hline
\end{tabular}

Fonte: Elaborado pelos autores, a partir dos dados da PNAD de 2011.

Figura 2: Probabilidades estimadas segundo o nível de escolaridade.

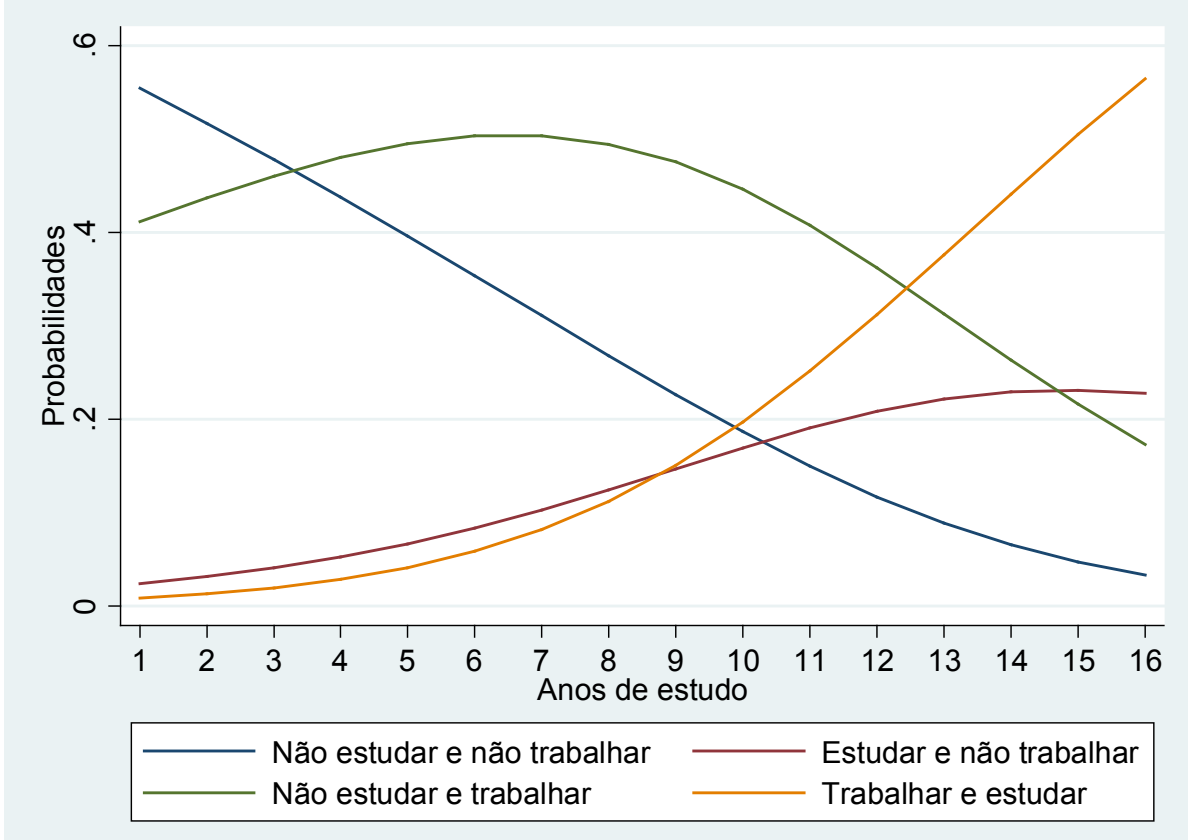

Fonte: Elaborado pelos autores, a partir dos dados da PNAD de 2011.

Ao comparar as áreas metropolitana e não-metropolitana no Paraná, verifica-se que a probabilidade de estar realizando ambas as atividades, e de não realizar nenhuma atividade, aumenta quando o jovem reside em área metropolitana. Já as opções de estudar e não trabalhar, e não estudar e trabalhar tem sua probabilidade maior na área não-metropolitana. 
Tabela 5: Probabilidades estimadas segundo o número de pessoas no domicílio.

\begin{tabular}{lcc}
\hline \multicolumn{1}{c}{ Categorias } & Região metropolitana & Região não metropolitana \\
\hline Não estudar e não trabalhar & 0,1863 & 0,1602 \\
Estudar e não trabalhar & 0,1669 & 0,1868 \\
Não estudar e trabalhar & 0,4082 & 0,4418 \\
Trabalhar e estudar & 0,2387 & 0,2113 \\
\hline
\end{tabular}

Fonte: Elaborado pelos autores, a partir dos dados da PNAD de 2011.

A literatura traz pesquisas também sobre a macrorregião brasileira, como a de Leite e Silva (2002) baseados no modelo logit multinomial utilizam dados da PNAD de 2009 para averiguar as influências de características individuais e das famílias para crianças e adolescentes com faixa etária entre 5 e 17 anos com residência nas regiões Nordeste e Sudeste brasileiras a respeito de suas escolhas ocupacionais e concluem que as atividades realizadas pelas crianças irão depender das condições de vida e do nível de pobreza aos quais estão inseridas. Quanto menor o nível de instrução de sua mãe, maior será a probabilidade de uma criança deixar a escola, porém as chances de trabalhar e estudar serão maiores se a criança residir na região Nordeste, enquanto que se morar na região sudeste a probabilidade de permanecer fora da força de trabalho será maior. Também se observou que é maior a probabilidade de crianças e adolescentes do sexo masculino participar do mercado de trabalho ao passo que as do sexo feminino apresentam maior chance de não fazer parte do mercado de trabalho.

O número de pessoas no domicílio foi investigado neste trabalho e percebeu-se também que quanto mais pessoas no domicílio maior a probabilidade do jovem escolher não estudar nem trabalhar (figura 3), essa probabilidade aumenta $2,1 \%$ a cada pessoa a mais residindo no domicílio. No caso da opção trabalhar e estudar há uma diminuição de 1,7\% nas chances, dado que uma pessoa a mais está residindo no domicílio. Os outros efeitos marginais para essa variável não podem ser considerados, pois não são significativos.

No que diz respeito a variável taxa de cômodos, note-se que quanto maior o valor referente a essa variável, maior a chance do jovem migrar da categoria somente estuda para a categoria somente trabalha. Na figura 4, é possível visualizar o processo de divergência entre a probabilidade de somente estudar e de somente trabalhar à medida que aumenta a taxa de cômodos. Os efeitos marginais (tabela 4) mostram que uma variação de uma unidade na taxa de cômodos faz a probabilidade do jovem somente estudar cair em 37,9\%, e faz as chances do jovem somente trabalhar aumentar $41,5 \%$. 


\section{Figura 3: Probabilidades estimadas segundo o número de pessoas no domicílio.}

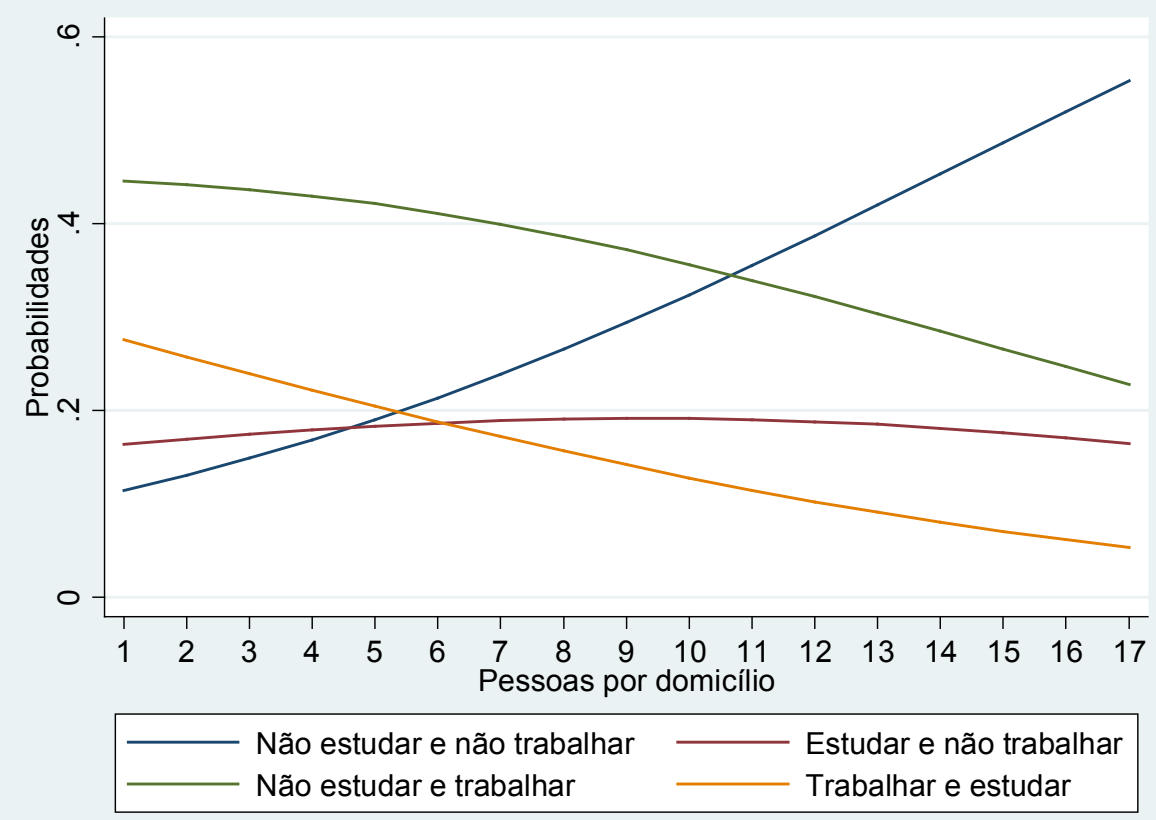

Fonte: Elaborado pelos autores, a partir dos dados da PNAD de 2011.

Figura 4: Probabilidades estimadas segundo a taxa de cômodos.

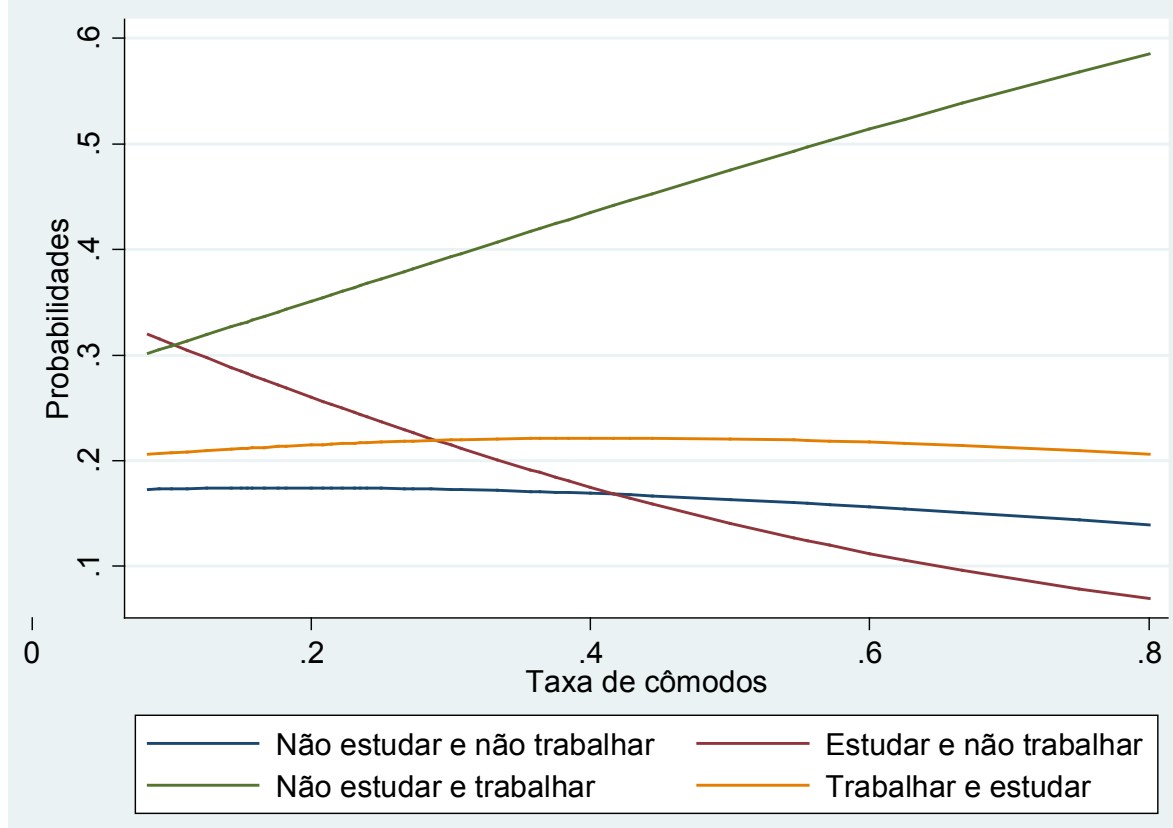

Fonte: Elaborado pelos autores, a partir dos dados da PNAD de 2011.

Uma alta taxa de cômodos indica condições precárias de moradia dos jovens, que por sua vez, mostra que a família do jovem dispõe de recursos 
limitados para suas atividades de subsistência. Dessa forma, os jovens precisam trabalhar para complementar os recursos necessários à subsistência. Esses resultados também foram encontrados por Leite e Silva (2002).

\section{Conclusão}

A partir dos resultados obtidos com o presente estudo observou-se que a probabilidade de jovens entre 15 e 24 anos, residentes no Paraná, estar somente trabalhando é cerca de $43,1 \%$, a probabilidade de não estar estudando é de aproximadamente $16,8 \%$.

As chances das jovens do sexo feminino apenas estudarem são maiores em relação aos jovens do sexo masculino. Já os jovens homens apresentam maiores chances de estarem inseridos no mercado de trabalho, somente trabalhando ou trabalhando e estudando. Os baixos salários oferecidos às mulheres e os fatores culturais podem traduzir esse fato

À medida que o jovem envelhece as chances de trabalhar e deixar de estudar aumentam, pois nessa situação, os salários crescem, a oferta de empregos torna-se mais frequente à medida que as restrições legais ao trabalho tendem a se reduzir, a atratividade e obrigatoriedade da escola diminuem, assim como aumentam a repetência, a insatisfação ou a desilusão com o sistema educacional.

O jovem que reside no Estado e que vive em companhia do cônjuge ou companheiro (a) tem uma maior probabilidade de abandonar os estudos em relação aos que não estão nessa situação, porque diminui sua disponibilidade de alocação de tempo e, com tempo limitado, o jovem opta por trabalhar ao invés de estudar. Para os homens, a consequência de viver com companheira ou cônjuge é mais prejudicial, do ponto de vista educacional, em relação às mulheres.

Outra evidência encontrada é que há uma tendência dos jovens de decidir trabalhar e estudar na medida que aumentam os seus anos de escolaridade, pois o trabalho lhes permite o acesso ao sistema escolar, principalmente ao ensino superior, tendo em vista que o estudo requer recursos financeiros, e o trabalho proporciona tal aporte.

Quanto mais pessoas no domicílio maior a probabilidade do jovem escolher não estudar nem trabalhar. Os resultados pouco precisos e confusos dessa variável em relação ao que se esperava leva pouca consideração das inferências obtidas.

Quando comparada as áreas metropolitana e não-metropolitana do Paraná, verificou-se que a probabilidade de estar realizando ambas as atividades, e de não realizar nenhuma atividade, aumenta quando o jovem reside em área metropolitana. Já as opções de estudar e não trabalhar, e não estudar e não trabalhar tem sua probabilidade reduzida quando o jovem mora em área metropolitana.

Finalmente, as evidências mostram que quanto maior a taxa de cômodos, maior a chance do jovem migrar da categoria somente estuda para a categoria somente trabalha, o que indica condições precárias de moradia dos jovens, que por sua vez, mostra que a família do jovem dispõe de recursos limitados para 
suas atividades de subsistência. Dessa forma, os jovens precisam trabalhar para complementar os recursos necessários à subsistência.

\section{Referências}

Barros, R. P. De, Mendonça, R. (1991). Infância e adolescência no Brasil: as consequências da pobreza diferenciadas por gênero, faixa etária e região de residência. Pesquisa e Planejamento Econômico, 21(2).

Blinder, D. A. (1983). On the variances of asymptotically normal estimators from complex survey. International Statistical Review, 51; p. 279-292.

Corseuil, C. H., Santos, D. D.; Foguel, M. N. (2001) Decisões críticas em idades críticas: a escolha dos jovens entre estudo e trabalho no Brasil e em outros países da América Latina.Texto para discussão, IPEA, 797.

Ferreira, F. F. G., Barros, R. P. de. (1999).The slippery slope: explaining the increase in extreme poverty in urban Brazil, 1976-1996. Revista de Econometria, 19(2).

Lam, D., Duryea, S. (1999).Effects of schooling on fertility, labor supply, and investments in children, with evidence from Brazil. Journal of Human Resources, 34(1); p. 160-192.

Leite, P. G. P. G.; Silva, D. B. N. (2002). Análise da situação ocupacional de crianças e adolescentes nas regiões Sudeste e Nordeste do Brasil utilizando informações da PNAD 1999. Revista Brasileira de Estudos de População, 19(2);.

Leme, M. C. Da S.; Wajnman, S.(2000). A alocação do tempo dos adolescentes brasileiros entre o trabalho e a escola. Anais. Encontro Brasileiro de Estudos Populacionais, Caxambu.

Lima, J. C. M.; Paixão, A. N. (2011). Análise dos Determinantes do Trabalho Infantil para Famílias Tocantinenses Utilizando o Modelo Logit Multinomial. Informe Gepec, 15(2); p. 88-104.

Mendonça, R. (2000). A oportunidade imperdível: expansão educacional e desenvolvimento humano no Brasil. Rio de Janeiro: UFRJ,(Tese de Doutorado).

Pessoa, D. G. C.; Silva, P. L. N. (1998). Análise de dados amostrais complexos. Trabalho apresentado no $13^{\circ}$ Simpósio Nacional de Probabilidade e Estatística, promovido pela Associação Brasileira de Estatística.

Pnad. Pesquisa Nacional por Amostra de Domicílios 2011. IBGE.

Santos, D. D. (2000). Desemprego e escolaridade: comentários sobre uma relação nada óbvia. Rio de Janeiro: IPEA.

Silva, N. E Kassouf, A. (2002)O trabalho e a escolaridade dos jovens brasileiros. Anais.XIII Encontro da Associação Brasileira de Estudos Populacionais, Ouro Preto.

Souza, N. R. M.; Cruz, L. C. R.; Souza, M. R.; Souza, P. C. (2001). A inserção dos jovens no mercado de trabalho. Belo Horizonte: Fundação João Pinheiro, Centro de Estatística e Informações. 